\title{
EFEITO DA APLICAÇÃO DE EXTRATOS AQUOSOS EM COUVE NA ALIMENTAÇÃO DE LAGARTAS DE ASCIA MONUSTE ORSEIS ${ }^{(1)}$
}

\author{
CESAR AUGUSTO MANFRÉ MEDEIROS ${ }^{(2)}$; ARLINDO LEAL BOIÇA JÚNIOR ${ }^{(3)}$
}

\begin{abstract}
RESUMO
Os efeitos de extratos aquosos de amêndoas de Azadirachta indica e frutos de Sapindus saponaria, aplicados em discos de folhas de couve (Brassica oleracea var. acephala) nas concentrações de 0,0117\% e 1,0342\% $(\mathrm{p} / \mathrm{v})$, respectivamente, foram estudados sobre a alimentação das lagartas de Ascia monuste orseis. Avaliouse a atratividade e o consumo de área foliar de lagartas de primeiro e terceiro ínstar durante 24 horas, em condições de laboratório $\left(T=25 \pm 2^{\circ} \mathrm{C}, \mathrm{UR}=60 \pm 10 \%\right.$ e fotofase $=12$ horas). Nos testes com e sem chance de escolha, para lagartas de primeiro ínstar e teste sem chance de escolha para lagartas de terceiro ínstar, não houve diferença quanto à atratividade das lagartas. No teste com chance de escolha para lagartas de terceiro ínstar, houve menor atratividade das lagartas pelos discos de folhas tratadas com S. saponaria, diferindo da testemunha. No decorrer de 24 horas de avaliações, pode-se observar 58,3\% de lagartas atraídas na testemunha, não diferindo de $A$. indica e diferindo de $S$. saponaria, com $39,3 \%$ e 2,4\% das lagartas atraídas, respectivamente. Quanto ao consumo de área foliar, o extrato de $S$. saponaria diminuiu o consumo de lagartas, em todos os testes realizados. Quando não tinham opção de escolha para se alimentar de folhas sem os extratos, as lagartas consumiram as folhas tratadas nas concentrações testadas, porém em menor quantidade. Os extratos testados neste experimento demonstram ter efeitos sobre a alimentação das lagartas de A. monuste orseis, possivelmente com propriedades deterrentes e/ou supressoras de alimentação.
\end{abstract}

Palavras-chave: Insecta, Pieridae, planta inseticida, nim, Brassica oleracea var. acephala.

\author{
ABSTRACT \\ EFFECT OF AQUEOUS VEGETAL EXTRACTS APPLICATION ON LARVAL \\ FEEDING BEHAVIOR OF ASCIA MONUSTE ORSEIS AT KALE
}

\begin{abstract}
The effects of aqueous extracts of Azadirachta indica almonds and of Sapindus saponaria fruits, applied on disks of kale leaves (Brassica oleracea var. acephala) at concentrations of $0.0117 \%$ and $1.0342 \%$ (w/v), respectively, were studied on larval feeding behavior of Ascia monuste orseis. Data on leaves attractiveness and consumption at first and third larval instar were taken during 24 hours $\left(25 \pm 2{ }^{\circ} \mathrm{C}\right.$ temperature, $60 \pm 10 \% \mathrm{RH}$ and 12 photophase). There was not difference in relation to attractiveness of caterpillars at first instar in tests with and without choice as well as caterpillar at third instar in tests without possibility of choice. In the test with possibility of choice for caterpillars of third instar had lesser attractiveness of the caterpillars for disks leaf treated with S. saponaria, differing to the control. During 24 hours of evaluations $58.3 \%$ of caterpillars were attracted to the control treatment which, did not differed to the $39.3 \%$ of A. indica treated disks. However, the treatments with $S$. saponaria, showed a $2.4 \%$ of the caterpillars attracted by observation, which was a significant difference. In addition, S. saponaria reduced the consumption of leaves by caterpillars in all the carried tests. When the caterpillars did not have feeding choice of leaves without extracts, consumption was performed with no difference among treated leaves, in all tested concentrations, however they consumed a lesser amount. The extracts tested in this experiment demonstrated effect on the feeding of the caterpillars of A. monuste orseis, possibly with deterrents properties and/or feeding suppressors.
\end{abstract}

Key words: Insecta, Pieridae, insecticidal plant, neem, Brassica oleracea var. acephala.

( $\left.{ }^{1}\right)$ Recebido para publicação em 2 de julho de 2004 e aceito em 8 de novembro de 2005.

$\left({ }^{2}\right)$ Acadêmico do Curso de Pós-Graduação em Agronomia (Entomologia Agrícola) da FCAV/UNESP - Jaboticabal (SP).

$\left({ }^{3}\right)$ Departamento de Fitossanidade da FCAV/UNESP, Via de Acesso Prof. Paulo Donato Castellane, s/n, 14884-900 Jaboticabal (SP). E-mail: aboicajr@fcav.unesp.br. 


\section{INTRODUÇÃO}

A couve, Brassica oleracea L. var. acephala D.C., é uma hortaliça com grande importância na nutrição humana, sendo muito produzida nas localidades do centro-sul do Brasil. É uma planta de temperaturas amenas, com melhor desenvolvimento no outono e inverno, porém, apresenta boa adaptação a climas variados (FILGUeIRA, 1982).

As pragas são um dos fatores que causam grandes perdas na produção dessa cultura. $\mathrm{O}$ curuquerê-da-couve, Ascia monuste orseis (Latreille) (Lepidoptera: Pieridae), é considerado uma das pragas-chave da cultura da couve, por sua ocorrência freqüente e elevada voracidade da lagarta, provocando intensa desfolha nas plantas (NOMURA e Yamashita, 1975; Vendramim e Martins, 1982; De BORTOLI et al., 1983; Gallo et al., 2002). Seu controle é realizado principalmente pela aplicação periódica de inseticidas (SALGADO, 1983; GALLO et al., 2002). Estes produtos químicos sintéticos podem acarretar diversos problemas, tais como resíduos nos alimentos, destruição de inimigos naturais, intoxicação de aplicadores e aparecimento de populações de pragas resistentes aos inseticidas (Roel et al. 2000b).

Produtos naturais extraídos de plantas são uma fonte de substâncias que podem ser utilizadas no controle de pragas, sendo compatíveis com programas de manejo integrado de pragas (MIP) (SHINFoON e YU-Tong, 1993) e têm adquirido importância como alternativa para o controle de insetos, reduzindo os efeitos negativos ocasionados pela aplicação descontrolada de inseticidas organossintéticos (VendRAmIM e SCAMPINI, 1997).

Extratos de pós de sementes de Azadirachta indica (A. Juss), também conhecida como nim, misturados ao substrato destinado ao transplantio das mudas de repolho, foram estudados por OsMAN e PORT (1990) sobre lagartas de terceiro ínstar de Pieris brassicae L. Esses autores verificaram seu efeito sistêmico, provocando a mortalidade de todas as lagartas, pela aplicação das doses de 16, 8, 4 e $2 \mathrm{~g}$ desse pó por kg de substrato.

O efeito da aplicação tópica de extrato metanólico de sementes de nim sobre formas imaturas de $P$. brassicae, importante pragas das crucíferas, foi demonstrado por OSMAN (1993). Nesse trabalho, larvas de quinto ínstar foram tratadas topicamente com 10 $\mu \mathrm{L}$ de extrato nas concentrações de $5 ; 2,5 ; 1,25$ e $0,625 \%$ com auxílio de um microaplicador, e mantidas sobre discos de folhas de repolho. Constatou-se que todas as larvas tratadas com extrato nas concentrações de
2,5 e $5 \%$ morreram ou resultaram em adultos defeituosos, e que a duração compreendida do quinto ínstar ao estágio adulto foi aumentada.

Estrela et al. (2003), estudando a toxicidade de amidas análogas à piperina em larvas de terceiro ínstar de A. monuste orseis e Spodoptera frugiperda (J. E. Smith), constataram que a $\mathrm{DL}_{50}$ (mg i.a./mg larva) da aplicação tópica das amidas $\mathrm{N}$-isopropil e $\mathrm{N}$-hexil para A. monuste orseis foram de 0,278 e 0,004 , respectivamente, e que para $S$. frugiperda foram de 1,359 e 0,613 respectivamente.

Com extrato aquoso de ramos de Trichilia pallida Swartz, à concentração de $1 \%$, verificou-se forte atividade inseticida, matando $100 \%$ das lagartas de S. frugiperda, quando aplicado em milho (TORRECILLAS e Vendramim, 2001).

VENDRAMIM e SCAMPINI (1997) verificaram nas lagartas de $S$. frugiperda alimentadas com folhas de milho tratadas com extratos de frutos de Melia azedarach (L.) menor peso, desenvolvimento mais lento e menor viabilidade larval.

Avaliando extratos de ramos e folhas de $T$. pallida em diferentes solventes, ROEL et al. (2000a) constataram 100 e $90 \%$ de mortalidade de lagartas de S. frugiperda para extrato acetônico de ramos e folhas, respectivamente, na concentração de $0,008 \%$ aplicados em folhas de milho, e 100\% de mortalidade em extrato metanólico para ramos e folhas também na concentração de $0,008 \%$.

TORRes et al. (2001) constataram $100 \%$ de mortalidade de larvas de Plutella xylostella (L.) quando alimentadas com folhas de couve tratadas com extratos aquosos de A. indica e Aspidosperma pyrifolium (Mart.), na concentração de $10 \%$.

Estudando o efeito de diversos extratos aquosos em relação a preferência para oviposição de P. xylostella em discos de folhas de couve, cultivar Geórgia, Medeiros et al. (2005) constataram que os extratos proporcionaram efeito deterrente na oviposição da praga, com destaque para extrato de frutos de Sapindus saponaria L. (sabão-de-soldado) e outros dois extratos de outras espécies vegetais, com índice de $100 \%$ de deterrência.

BOIÇA JUNIOR et al. (2005), avaliando o efeito de extratos aquosos de plantas na concentração de $10 \%$ no desenvolvimento de $P$. xylostella, sobre discos de folha de couve, concluíram que os extratos de $S$. saponaria e outros três extratos proporcionaram $100 \%$ de mortalidade das larvas dessa praga, e o extrato dos frutos de S. saponaria propiciou mortalidade maior à das folhas, com valores de $100 \%$ e $62,5 \%$ respectivamente. 
FANCELLI e VENDRAMIM (1993) estudaram a nãopreferência para alimentação em lagartas de primeiro ínstar de $A$. monuste orseis em diferentes genótipos de couve, verificando que esses não exerceram efeito significativo sobre a preferência alimentar destas lagartas, sugerindo que a seleção hospedeira nesta espécie é realizada exclusivamente pelos adultos.

Considerando a importância de A. monuste orseis, que causa perdas significativas na cultura da couve, e aos efeitos indesejáveis decorrentes de aplicações de inseticidas para seu controle, objetivouse com este trabalho avaliar os efeitos de extratos aquosos de amêndoas de $A$. indica e de frutos de $S$. saponaria, aplicados em folhas de couve, sobre a alimentação de lagartas de $A$. monuste orseis, em condições de laboratório.

\section{MATERIAL E MÉTODOS}

O trabalho foi desenvolvido em campo, em Jaboticabal, SP, cujas condições utilizadas para a criação do inseto e desenvolvimento dos experimentos foram: temperatura de $25 \pm 2{ }^{\circ} \mathrm{C}$, umidade relativa de $60 \pm 10 \%$ e fotofase de 12 horas.

Plantas de couve, cultivar Georgia foram cultivadas em campo para utilizar na criação das lagartas e nos experimentos. As sementes foram semeadas em casa de vegetação, em bandejas de isopor de 128 células, contendo substrato Plantmax ${ }^{\circledR}$. Após 35 dias, foram transplantadas para canteiro definitivo no campo, recebendo tratos culturais padrão para a cultura, como adubações e capina. Irrigações por aspersão foram realizadas quando necessário.

\section{Ovos do inseto A. monuste orseis}

Ovos do inseto foram coletados em culturas de couve e repolho em área da Faculdade de Ciências Agrárias e Veterinárias (UNESP), Campus de Jaboticabal, SP, conduzidos ao laboratório e acondicionados em placas de Petri contendo papel filtro levemente umedecido. As lagartas recémeclodidas foram transferidas para gaiolas constituídas por tubos de PVC de $20 \mathrm{~cm}$ de diâmetro e $30 \mathrm{~cm}$ de altura, permanecendo até a fase de pupa e emergência dos adultos. Para evitar a fuga de lagartas e facilitar o manuseio, esses tubos foram colocados sobre pratos de PVC e sua extremidade superior tampada com tecido tipo "voile". As lagartas foram alimentadas com folhas de couve, as quais foram trocadas diariamente por outras provindas da plantação no campo. As pupas oriundas da criação permaneciam nos tubos de PVC até emergência dos adultos, para posterior seagem. Os adultos foram liberados em uma gaiola no campo de $4 \mathrm{~m}$ de comprimento, $2 \mathrm{~m}$ de largura e $2 \mathrm{~m}$ de altura, cercada com tela anti-afídeo, com um copo com mel a $10 \%$ para alimentação e também com um vaso com uma planta de couve para oviposição. Os ovos foram recolhidos diariamente, recortando-se a parte da folha na qual estavam fixados e levados ao laboratório para dar continuidade à criação e serem utilizados nos experimentos.

\section{Obtenção dos extratos aquosos}

Amêndoas de plantas de $A$. indica e frutos de S. saponaria, pertencentes às famílias Meliaceae e Sapindaceae, respectivamente, foram coletados na FCAV/UNESP, Jaboticabal, e colocados para secagem em estufa à temperatura entre 35 e $38^{\circ} \mathrm{C}$, até peso constante. Em seguida, foram moídas utilizando-se moinho Marconi modelo MA6801, obtendo-se um pó uniforme, que foi utilizado no preparo de suspensões aquosas e posterior obtenção dos extratos utilizados como tratamentos em aplicações nas folhas de couve.

Para a avaliação do efeito sobre a alimentação das lagartas de $A$. monuste orseis em discos de folhas de couve tratadas com extratos vegetais aquosos, foram preparadas suspensões com água destilada nas concentrações da $C L_{50}$ determinadas anteriormente (MEDEIROS, 2004), sendo de $0,0117 \%$ e $1,0342 \%$ (peso/volume) para $A$. indica e $S$. saponaria respectivamente.

As suspensões permaneceram em repouso por 24 horas, com o propósito de extrair os compostos hidrossolúveis. Após, foram filtradas, utilizando-se tecido tipo "voile", para obtenção dos extratos em cada concentração. Discos de 3,5 cm de diâmetro de folhas de couve foram mergulhados por um minuto no extrato e colocados sobre papel-toalha ao ar livre, por 30 minutos, para perda do excesso de umidade superficial, antes de serem oferecidas às lagartas.

\section{Bioensaios}

Nos testes com livre chance de escolha para estudar a orientação de lagartas de primeiro ínstar (recém-eclodidas) e terceiro ínstar, utilizou-se uma arena constituída de uma placa de Petri, com diâmetro de $15 \mathrm{~cm}$, contendo papel filtro levemente umedecido no fundo. Em cada placa colocou-se um disco de folha de couve tratado com cada extrato vegetal e um disco testemunha, tratado apenas com água destilada, dispostos equidistantes entre si e próximos da borda da placa. No experimento com lagartas de primeiro instar, foram liberadas 15 delas por placa e com as de terceiro ínstar, seis por placa. 
Nos testes sem chance de escolha também com lagartas de primeiro ínstar (recém-eclodidas) e terceiro ínstar, colocou-se um único disco de folha tratado por placa de Petri, contendo papel filtro levemente umedecido no fundo. No experimento com lagartas de primeiro ínstar foram liberadas cinco delas por placa e com as de terceiro ínstar, duas por placa.

As avaliações do número de lagartas em cada disco de folha foram feitas após 3, 5, 10, 15 e 30 minutos e 1, 2, 4, 6 e 24 horas após sua liberação. Após 24 horas da liberação das lagartas, o experimento foi interrompido e os discos de folhas submetidos a um aparelho medidor de área foliar, modelo LI 3050A, para determinar a área foliar consumida pelas lagartas.

O delineamento experimental utilizado foi inteiramente casualizado, com três tratamentos (dois extratos vegetais + testemunha) e dez repetições. Os resultados foram submetidos à análise de variância e as médias comparadas pelo teste de Tukey $(\alpha=0,05)$.

\section{RESULTADOS E DISCUSSÃO}

A atratividade das lagartas pelos discos de folhas de couve, tratados com os extratos aquosos, não diferiu da testemunha nos testes com e sem chance de escolha, para lagartas de primeiro ínstar, e teste sem chance de escolha para lagartas de terceiro ínstar (Tabelas 1, 3 e 7). A atratividade obtida a partir do total de lagartas no intervalo entre três e 15 minutos e na média das lagartas no intervalo entre um minuto e 24 horas também não diferiram nesses testes (Tabelas 2, 4 e 8).
Apesar de não ter havido diferença significativa nos testes, pode-se notar, no geral, tendência à maior repelência das lagartas pelos discos tratados com S. saponaria, seguido dos tratados com A. indica, em relação à testemunha, tratada apenas com água destilada.

No teste com livre chance de escolha para lagartas de terceiro ínstar, constatou-se maior efeito repelente dos extratos nos discos de folhas tratadas com S. saponaria, com um menor número de lagartas atraídas, diferindo da testemunha (Tabela 5). Durante a primeira hora de avaliações houve efeito intermediário do extrato de $A$. indica na atratividade das lagartas, porém, após este tempo, os valores não diferiram daqueles da testemunha (Tabela 5). Nesse teste, houve diferença também na atratividade obtida a partir do total de lagartas no intervalo entre 3 e 15 minutos e na média das lagartas no intervalo entre 3 minutos e 24 horas, para o extrato de $S$. saponaria, o qual diferiu da testemunha (Tabela 6).

Analisando-se os dados das Tabelas 1 e 5, em que as lagartas tinham livre chance de escolha entre os discos de folhas com os extratos e testemunha, podese observar que as lagartas apresentaram baixa mobilidade entre os discos, ou seja, a maioria das lagartas dirigiram-se aos discos de folhas e permaneceram neles durante o decorrer das avaliações.

Fancelli e Vendramim (1993) verificaram que lagartas recém-eclodidas de $A$. monuste orseis praticamente não se movimentam, permanecendo no mesmo local onde é feita a postura. BARROs-BELLANDA e Zucoloto (2003) comentaram que lagartas de $A$. monuste orseis migram para outro hospedeiro em busca de alimento quando estão no início do quinto ínstar, e durante a migração mostram baixa capacidade de detectar seu hospedeiro.

Tabela 1. Número médio de lagartas de primeiro ínstar de Ascia monuste orseis em dez avaliações, obtidas em discos de folhas de couve tratados com extratos aquosos de Azadirachta indica e Sapindus saponaria, em testes com livre chance de escolha. T: $25 \pm$ $2{ }^{\circ} \mathrm{C}$; UR: $60 \pm 10 \%$; Fotofase: 12 horas

\begin{tabular}{|c|c|c|c|c|c|c|c|c|c|c|}
\hline \multirow{3}{*}{ Tratamentos } & \multicolumn{10}{|c|}{ Número médio de lagartas atraídas ${ }^{*}$} \\
\hline & \multicolumn{5}{|c|}{ Minutos } & \multicolumn{5}{|c|}{ Horas } \\
\hline & 3 & 5 & 10 & 15 & 30 & 1 & 2 & 4 & 6 & 24 \\
\hline Testemunha & - & $0 \mathrm{a}$ & $0,4 \mathrm{a}$ & $0,6 \mathrm{a}$ & $1,3 \mathrm{a}$ & $2,5 \mathrm{a}$ & 4,4 a & 5,1 a & 5,1 a & $5,2 \mathrm{a}$ \\
\hline A. indica & - & $0 \mathrm{a}$ & $0,7 \mathrm{a}$ & $1,3 \mathrm{a}$ & $1,4 \mathrm{a}$ & $2,7 \mathrm{a}$ & $4,1 \mathrm{a}$ & $6,1 \mathrm{a}$ & $6,3 \mathrm{a}$ & $6,1 \mathrm{a}$ \\
\hline S. saponaria & - & $0,1 \mathrm{a}$ & $0,4 \mathrm{a}$ & $0,5 \mathrm{a}$ & $0,9 \mathrm{a}$ & $2,4 \mathrm{a}$ & $3,5 \mathrm{a}$ & $3,6 \mathrm{a}$ & $3,4 \mathrm{a}$ & $3,6 \mathrm{a}$ \\
\hline F (tratamento) & - & 1,00 & 0,30 & 1,10 & 0,30 & 0,16 & 0,31 & 1,03 & 1,29 & 1,00 \\
\hline
\end{tabular}

* Médias seguidas da mesma letra não diferem estatisticamente pelo teste de Tukey, a 5\% de probabilidade. Para a análise, os dados foram transformados em $(x+0,5) \frac{1 / 2}{2}$. 
Tabela 2. Número médio ( \pm EP) de lagartas de primeiro ínstar de Ascia monuste orseis nos intervalos de três a 15 minutos e de três minutos a 24 horas e consumo médio $( \pm \mathrm{EP})$ de área foliar $\left(\mathrm{cm}^{2}\right)$, obtidos em discos de folhas de couve tratados com extratos aquosos de Azadirachta indica e Sapindus saponaria, em testes com livre chance de escolha. T: $25 \pm 2{ }^{\circ} \mathrm{C}$; UR: $60 \pm 10 \%$; Fotofase: 12 horas

\begin{tabular}{lccc}
\hline Tratamentos & \multicolumn{2}{c}{ Número médio de lagartas atraídas } & Consumo médio \\
\cline { 2 - 4 } & 3 a 15 minutos ${ }^{(1)}$ & 3 minutos a 24 horas ${ }^{(2)}$ & de área foliar $\left(\mathrm{cm}^{2}\right)$ \\
\hline Testemunha & $1,0 \pm 0,66 \mathrm{a}$ & $2,5 \pm 0,59 \mathrm{a}$ & $0,312 \pm 0,066 \mathrm{a}$ \\
A. indica & $2,0 \pm 0,81 \mathrm{a}$ & $2,9 \pm 0,71 \mathrm{a}$ & $0,327 \pm 0,061 \mathrm{a}$ \\
S. saponaria & $1,0 \pm 0,66 \mathrm{a}$ & $1,8 \pm 0,80 \mathrm{a}$ & $0,106 \pm 0,048 \mathrm{~b}$ \\
\hline F (tratamento) & 0,72 & 0,71 & $4,92 *$ \\
\hline
\end{tabular}

$\mathrm{EP}=$ erro padrão.

Médias seguidas da mesma letra não diferem estatisticamente pelo teste de Tukey, ao nível de $5 \%$ de probabilidade. Para a análise, os dados foram transformados em $(x+0,5) \frac{1}{2}$.

$\left({ }^{1}\right)$ Total de lagartas nas avaliações de 3, 5, 10 e 15 minutos.

$\left({ }^{2}\right)$ Média do número de lagartas nas onze avaliações da atratividade.

Tabela 3. Número médio de lagartas de primeiro ínstar de Ascia monuste orseis em dez avaliações, obtidas em discos de folhas de couve tratados com extratos aquosos de Azadirachta indica e Sapindus saponaria, em testes sem chance de escolha. T: $25 \pm 2{ }^{\circ} \mathrm{C}$; UR: $60 \pm 10 \%$; Fotofase: 12 horas

\begin{tabular}{|c|c|c|c|c|c|c|c|c|c|c|}
\hline \multirow{3}{*}{ Tratamentos } & \multicolumn{10}{|c|}{ Número médio de lagartas atraídas* } \\
\hline & \multicolumn{5}{|c|}{ Minutos } & \multicolumn{5}{|c|}{ Horas } \\
\hline & 3 & 5 & 10 & 15 & 30 & 1 & 2 & 4 & 6 & 24 \\
\hline Testemunha & $0,2 \mathrm{a}$ & $0,4 \mathrm{a}$ & $1,2 \mathrm{a}$ & $1,3 \mathrm{a}$ & $2,0 \mathrm{a}$ & $2,3 \mathrm{a}$ & $3,7 \mathrm{a}$ & $4,0 \mathrm{a}$ & $4,6 \mathrm{a}$ & $5,0 \mathrm{a}$ \\
\hline A. indica & $0,0 \mathrm{a}$ & $0,2 \mathrm{a}$ & $0,7 \mathrm{a}$ & $0,8 \mathrm{a}$ & $1,1 \mathrm{a}$ & $1,8 \mathrm{a}$ & 3,3 a & $4,3 \mathrm{a}$ & $4,8 \mathrm{a}$ & $4,9 \mathrm{a}$ \\
\hline S. saponaria & $0,0 \mathrm{a}$ & $0,0 \mathrm{a}$ & 0,4 a & 0,6 a & 0,7 a & $0,4 \mathrm{a}$ & $3,1 \mathrm{a}$ & $3,6 \mathrm{a}$ & 3,9 a & $4,6 \mathrm{a}$ \\
\hline F (tratamento) & 1,00 & 1,81 & 0,78 & 0,46 & 0,95 & 2,42 & 0,23 & 0,48 & 1,97 & 0,81 \\
\hline
\end{tabular}

* Médias seguidas da mesma letra não diferem estatisticamente pelo teste de Tukey, a 5\% de probabilidade. Para a análise, os dados foram transformados em $(x+0,5) \frac{1}{1 / 2}$.

Tabela 4. Número médio $( \pm$ EP) de lagartas de primeiro ínstar de Ascia monuste orseis nos intervalos de três a 15 minutos e de três minutos a 24 horas e consumo médio $( \pm \mathrm{EP})$ de área foliar $\left(\mathrm{cm}^{2}\right)$, obtidos em discos de folhas de couve tratados com extratos aquosos de Azadirachta indica e Sapindus saponaria, em testes sem chance de escolha. T: $25 \pm 2{ }^{\circ} \mathrm{C}$; UR: $60 \pm$ $10 \%$; Fotofase: 12 horas

\begin{tabular}{lccc}
\hline \multirow{2}{*}{ Tratamentos } & \multicolumn{2}{c}{ Número médio de lagartas atraídas } & Consumo médio de \\
\cline { 2 - 3 } & 3 a 15 minutos ${ }^{(1)}$ & 3 minutos a 24 horas ${ }^{(2)}$ & área foliar $\left(\mathrm{cm}^{2}\right)$ \\
\hline Testemunha & $3,1 \pm 1,31 \mathrm{a}$ & $2,5 \pm 0,67 \mathrm{a}$ & $0,287 \pm 0,033 \mathrm{a}$ \\
A. indica & $1,7 \pm 0,75 \mathrm{a}$ & $2,2 \pm 0,25 \mathrm{a}$ & $0,271 \pm 0,033 \mathrm{a}$ \\
S. saponaria & $1,0 \pm 0,40 \mathrm{a}$ & $1,7 \pm 0,74 \mathrm{a}$ & $0,135 \pm 0,026 \mathrm{~b}$ \\
\hline F (tratamento) & 0,69 & 1,67 & $6,91 * *$ \\
\hline
\end{tabular}

$\mathrm{EP}=$ erro padrão.

Médias seguidas da mesma letra não diferem estatisticamente pelo teste de Tukey, a 5\% de probabilidade. Para a análise, os dados foram transformados em $(x+0,5) \frac{1}{2}$.

$\left({ }^{1}\right)$ Total de lagartas nas avaliações de 3, 5, 10 e 15 minutos.

$\left.{ }^{2}\right)$ Média do número de lagartas nas onze avaliações da atratividade. 
Tabela 5. Número médio de lagartas de terceiro ínstar de Ascia monuste orseis em dez avaliações, obtidas em discos de folhas de couve tratados com extratos aquosos de Azadirachta indica e Sapindus saponaria, em testes com livre chance de escolha. T: $25 \pm$ $2{ }^{\circ} \mathrm{C}$; UR: $60 \pm 10 \%$; Fotofase: 12 horas

\begin{tabular}{|c|c|c|c|c|c|c|c|c|c|c|}
\hline \multirow{3}{*}{ Tratamentos } & \multicolumn{10}{|c|}{ Número médio de lagartas atraídas* } \\
\hline & \multicolumn{5}{|c|}{ Minutos } & \multicolumn{5}{|c|}{ Horas } \\
\hline & 3 & 5 & 10 & 15 & 30 & 1 & 2 & 4 & 6 & 24 \\
\hline Testemunha & $1,7 \mathrm{a}$ & $1,9 \mathrm{a}$ & $2,1 \mathrm{a}$ & $2,1 \mathrm{a}$ & $2,6 \mathrm{a}$ & $2,7 \mathrm{a}$ & $2,5 \mathrm{a}$ & $2,6 \mathrm{a}$ & $2,7 \mathrm{a}$ & $2,7 \mathrm{a}$ \\
\hline A. indica & $0,7 \mathrm{ab}$ & $0,9 \mathrm{ab}$ & $1,1 \mathrm{ab}$ & $1,4 \mathrm{ab}$ & $1,5 \mathrm{ab}$ & $1,7 \mathrm{ab}$ & $1,8 \mathrm{a}$ & $1,9 \mathrm{a}$ & $2,3 \mathrm{a}$ & $2,6 \mathrm{a}$ \\
\hline S. saponaria & $0,1 \mathrm{~b}$ & $0,1 \mathrm{~b}$ & $0,2 \mathrm{~b}$ & $0,1 \mathrm{~b}$ & $0,1 \mathrm{~b}$ & $0,1 \mathrm{~b}$ & $0,1 \mathrm{~b}$ & $0,1 \mathrm{~b}$ & $0,2 \mathrm{~b}$ & $0,2 \mathrm{~b}$ \\
\hline F (tratamento) & $6,12^{* *}$ & $6,09^{* *}$ & $5,78^{* *}$ & $5,92^{* *}$ & $8,31^{* *}$ & $7,79^{* *}$ & $7,72^{* *}$ & $7,02^{* *}$ & $8,22^{* *}$ & $11,89^{* *}$ \\
\hline
\end{tabular}

* Médias seguidas da mesma letra não diferem estatisticamente pelo teste de Tukey, a 5\% de probabilidade. Para a análise, os dados foram transformados em $(x+0,5) \frac{1}{2}$.

Tabela 6. Número médio $( \pm$ EP) de lagartas terceiro ínstar de Ascia monuste orseis nos intervalos de três a 15 minutos e de três minutos a 24 horas e consumo médio $( \pm \mathrm{EP})$ de área foliar $\left(\mathrm{cm}^{2}\right)$, obtidos em discos de folhas de couve tratados com extratos aquosos de Azadirachta indica e Sapindus saponaria, em testes com livre chance de escolha. T: $25 \pm 2{ }^{\circ} \mathrm{C}$; UR: $60 \pm$ 10\%; Fotofase: 12 horas

\begin{tabular}{lccc}
\hline \multirow{2}{*}{ Tratamentos } & \multicolumn{2}{c}{ Número médio de lagartas atraídas } & Consumo médio de \\
\cline { 2 - 3 } & 3 a 15 minutos ${ }^{(1)}$ & 3 minutos a 24 horas ${ }^{(2)}$ & área foliar $\left(\mathrm{cm}^{2}\right)$ \\
\hline Testemunha & $7,8 \pm 1,89 \mathrm{a}$ & $2,2 \pm 0,38 \mathrm{a}$ & $11,234 \pm 1,671 \mathrm{a}$ \\
A. indica & $4,1 \pm 1,49 \mathrm{ab}$ & $1,5 \pm 0,84 \mathrm{a}$ & $8,428 \pm 1,176 \mathrm{a}$ \\
S. saponaria & $0,5 \pm 0,32 \mathrm{~b}$ & $0,1 \pm 0,05 \mathrm{~b}$ & $1,748 \pm 0,278 \mathrm{~b}$ \\
\hline F (tratamento) & $6,74^{* *}$ & $11,59 * *$ & $18,60 * *$ \\
\hline
\end{tabular}

$\mathrm{EP}=$ erro padrão.

Médias seguidas da mesma letra não diferem estatisticamente pelo teste de Tukey, ao nível de 5\% de probabilidade. Para a análise, os dados foram transformados em $(x+0,5) \frac{1}{1}$.

$\left({ }^{1}\right)$ Total de lagartas nas avaliações de 3, 5, 10 e 15 minutos.

$\left({ }^{2}\right)$ Média do número de lagartas nas onze avaliações da atratividade.

Tabela 7. Número médio de lagartas de terceiro ínstar de Ascia monuste orseis em dez avaliações, obtidas em discos de folhas de couve tratados com extratos aquosos de Azadirachta indica e Sapindus saponaria, em testes sem chance de escolha. T: $25 \pm 2{ }^{\circ} \mathrm{C}$; UR: $60 \pm 10 \%$; Fotofase: 12 horas

\begin{tabular}{|c|c|c|c|c|c|c|c|c|c|c|}
\hline \multirow{3}{*}{ Tratamentos } & \multicolumn{10}{|c|}{ Número médio de lagartas atraídas* } \\
\hline & \multicolumn{5}{|c|}{ Minutos } & \multicolumn{5}{|c|}{ Horas } \\
\hline & 3 & 5 & 10 & 15 & 30 & 1 & 2 & 4 & 6 & 24 \\
\hline Testemunha & $0,3 \mathrm{a}$ & 0,4 a & $1,5 \mathrm{a}$ & $1,7 \mathrm{a}$ & $1,7 \mathrm{a}$ & $1,8 \mathrm{a}$ & $1,7 \mathrm{a}$ & 1,9 a & $1,9 \mathrm{a}$ & $1,7 \mathrm{a}$ \\
\hline A. indica & $0,2 \mathrm{a}$ & $1,2 \mathrm{a}$ & $1,6 \mathrm{a}$ & $1,6 \mathrm{a}$ & $1,7 \mathrm{a}$ & $1,7 \mathrm{a}$ & $1,7 \mathrm{a}$ & $1,7 \mathrm{a}$ & $1,7 \mathrm{a}$ & $1,8 \mathrm{a}$ \\
\hline S. saponaria & $0,2 \mathrm{a}$ & $1,1 \mathrm{a}$ & $1,1 \mathrm{a}$ & $1,4 \mathrm{a}$ & $1,3 \mathrm{a}$ & $1,6 \mathrm{a}$ & $1,5 \mathrm{a}$ & $1,8 \mathrm{a}$ & $1,7 \mathrm{a}$ & $1,3 \mathrm{a}$ \\
\hline F (tratamento) & 0,17 & 3,22 & 1,55 & 0,58 & 1,19 & 0,42 & 0,28 & 0,59 & 0,43 & 2,16 \\
\hline
\end{tabular}

* Médias seguidas da mesma letra não diferem estatisticamente pelo teste de Tukey, a 5\% de probabilidade. Para a análise, os dados foram transformados em $(x+0,5) \frac{1}{1} 2$. 
Analisando os dados no teste com livre chance de escolha para lagartas de terceiro ínstar (Tabela 6), no intervalo de 3 a 15 minutos, pode-se observar o total médio de 7,8 lagartas atraídas no tratamento testemunha, ou seja, $62,9 \%$ das lagartas, diferindo do tratamento com o extrato de $S$. saponaria, com a média de 0,5 lagartas, representando $4,0 \%$ do total.

Nas dez observações realizadas nesse teste, desde 3 minutos até 24 horas, pode-se notar um número médio de lagartas atraídas de 2,2 para a testemunha, representando $58,3 \%$ do total das lagartas, não diferindo de $A$. indica e diferente de S. saponaria, com média, respectivamente,de 1,5 (39,3\%) e $0,1(2,4 \%)$ lagartas atraídas por observação (Tabela 6). Esse baixo número médio de lagartas atraídas no tratamento com S. saponaria demonstra uma provável existência de substâncias repelentes nesse extrato.

Quanto ao consumo de área foliar, houve diferença significativa para o tratamento com $S$. saponaria em relação aos outros tratamentos em todos os testes realizados (Tabelas 2, 4, 6 e 8). No teste sem chance de escolha para lagartas de terceiro ínstar, no tratamento com $A$. indica ocorreram valores intermediários (Tabela 8).

O menor consumo das lagartas nas folhas tratadas revela que os extratos podem conter substâncias deterrentes à alimentação do inseto.

No teste com chance de escolha, com lagartas de terceiro ínstar, as lagartas reduziram o consumo foliar de $9,486 \mathrm{~cm}^{2}$ do tratamento com o extrato de S. saponaria em relação à testemunha, com consumo médio de $11,234 \mathrm{~cm}^{2}$ (Tabela 6). Essa diferença na área foliar consumida pelas lagartas representa cerca de $84,4 \%$ de redução. No teste sem chance de escolha, essa redução foi de $2,037 \mathrm{~cm}^{2}$ em relação à testemunha, com consumo foliar de $8,912 \mathrm{~cm}^{2}$ (Tabela 8 ), representando $22,9 \%$ de redução.

Essa redução na área foliar consumida também foi constatada nos testes com lagartas de primeiro ínstar. No teste com chance de escolha, houve uma redução de $0,206 \mathrm{~cm}^{2}$, em comparação à testemunha, com $0,312 \mathrm{~cm}^{2}$ (Tabela 2), o que representa $66,0 \%$ de redução. No teste sem chance de escolha, essa redução foi de $0,152 \mathrm{~cm}^{2}$ no tratamento com $S$. saponaria, em relação à testemunha, com 0,287 $\mathrm{cm}^{2}$ de consumo (Tabela 4), correspondendo a 52,9\% de redução. Essa diferença, quanto ao consumo de área foliar, entre os testes com e sem chance de escolha para um mesmo ínstar das lagartas, provavelmente seja devido ao maior número de lagartas liberadas em cada repetição no teste com chance de escolha. Assim, houve maior concentração de lagartas nos discos de folhas testemunhas, havendo maior consumo foliar.

Pelos resultados obtidos nos testes sem chance de escolha com redução significativa no consumo foliar pelas lagartas, principalmente no tratamento com o extrato de $S$. saponaria, contata-se que, quando não tem opção de escolha para se alimentar de folhas sem os extratos, as lagartas podem consumir as folhas mesmo estando tratadas nas concentrações testadas, porém com menor consumo, reduzindo assim os danos causados às plantas e diminuindo os prejuízos causados por essa praga.

Tabela 8. Número médio ( \pm EP) de lagartas terceiro ínstar de Ascia monuste orseis nos intervalos de 3 a 15 minutos e de 3 minutos a 24 horas e consumo médio $( \pm \mathrm{EP})$ de área foliar $\left(\mathrm{cm}^{2}\right)$, obtidos em discos de folhas de couve tratados com extratos aquosos de Azadirachta indica e Sapindus saponaria, em testes sem chance de escolha. T: $25 \pm 2{ }^{\circ} \mathrm{C}$; UR: $60 \pm 10 \%$; Fotofase: 12 horas

\begin{tabular}{|c|c|c|c|}
\hline \multirow{2}{*}{ Tratamentos } & \multicolumn{2}{|c|}{ Número médio de lagartas atraídas } & \multirow{2}{*}{$\begin{array}{l}\text { Consumo médio de } \\
\text { área foliar }\left(\mathrm{cm}^{2}\right)\end{array}$} \\
\hline & 3 a 15 minutos & 3 minutos a 24 horas ${ }^{(2)}$ & \\
\hline Testemunha & $4,0 \pm 0,45 \mathrm{a}$ & $1,6 \pm 0,29 \mathrm{a}$ & $8,912 \pm 0,482 \mathrm{a}$ \\
\hline A. indica & $4,6 \pm 0,65 \mathrm{a}$ & $1,4 \pm 0,12 \mathrm{a}$ & $8,141 \pm 0,695 \mathrm{ab}$ \\
\hline S. saponaria & $3,8 \pm 0,54 \mathrm{a}$ & $1,2 \pm 0,08 \mathrm{a}$ & $6,875 \pm 0,333 b$ \\
\hline F (tratamento) & 0,26 & 1,37 & $3,66 *$ \\
\hline
\end{tabular}

$\mathrm{EP}=$ erro padrão.

Médias seguidas da mesma letra não diferem estatisticamente pelo teste de Tukey, a 5\% de probabilidade. Para a análise, os dados foram transformados em $(x+0,5) \frac{1}{1 / 2}$.

$\left({ }^{1}\right)$ Total de lagartas nas avaliações de 3, 5, 10 e 15 minutos.

$\left(^{2}\right)$ Média do número de lagartas nas onze avaliações da atratividade. 
A redução na área foliar consumida pelas lagartas demonstra o efeito sobre sua alimentação, provavelmente devido a substâncias deterrentes e/ou supressoras de alimentação presentes no extrato de S. saponaria. Esses dados obtidos podem ser importantes, pois em plantas no campo, induzirá a uma redução no consumo foliar, podendo conseqüentemente reduzir os danos causados pela praga. Em testes realizados por MedeIRos et al. (2005), foram observados fatos semelhantes pelo uso de extratos de frutos de $S$. saponaria, porém, em relação à oviposição de $P$. xylostella em folhas de couve, com índice de $100 \%$ de deterrência.

Alguns índices obtidos de repelência e consumo de área foliar, principalmente no tratamento com $A$. indica, próximos aos obtidos na testemunha, provavelmente são devido às baixas concentrações utilizadas, não sendo suficientes para uma ação efetiva contra a praga.

\section{CONCLUSÕES}

1. Em testes de livre chance de escolha, a aplicação de extrato de $S$. saponaria em folhas de couve repele lagartas de terceiro ínstar, de A. monuste orseis; todavia essa menor atratividade desaparece em testes sem chance de escolha.

2. O extrato de S. saponaria na concentração de $1,0342 \%$ diminui o consumo de lagartas de $A$. monuste orseis em couve.

3. Quando não tem opção de escolha para se alimentar de folhas sem os extratos, as lagartas consomem as folhas tratadas nas concentrações testadas, porém em menor quantidade.

\section{REFERÊNCIAS}

BARROS-BELLANDA, H. C. H.; ZUCOLOTO, F. S. Importance of larval migration (dispersal) for the survival of Ascia monuste orseis (Godart) (Lepidoptera: Pieridae). Neotropical Entomology, Londrina, v. 32, n. 1, p. 11-17, 2003.

BOIÇA JUNIOR, A. L.; MEDEIROS, C. A. M.; TORRES, A. L.; CHAGAS FILHO, N. R. Efeito de extratos aquosos de plantas no desenvolvimento de Plutella xylostella (L.) (Lepidoptera: Plutellidae) em couve. Arquivos do Insituto Biológico, São Paulo, v.72, n.1, p.45-50, 2005.

DE BORTOLI, S. A.; BANZATO, D. A.; FORNER, A. C. Aspectos biológicos comparados de Ascia monuste orseis (Latreille, 1819) (Lepidoptera: Pieridae) em três cultivares de couve (Brassica oleracea L. var. acephala). Anais da Sociedade Entomológica do Brasil, Jaboticabal, v. 12, n. 2, p. 283-294, 1983.
ESTRELA, J. L. V.; GUEDES, R. N. C.; MALTHA, C. R. A.; FAZOLIN, M. Toxicidade de amidas análogas à piperina a larvas de Ascia monuste orseis Godart (Lepidóptera: Pieridae) e Spodoptera frugiperda (J. E. Smith) (Lepidoptera: Noctuidae). Neotropical Entomology, Londrina, v.32, n.2, p.343-346, 2003.

FANCELLI, M.; VENDRAMIM, J. D. Não preferência para alimentação e oviposição de Ascia monuste orseis (Godart) (Lepdoptera: Pieridae) em cultivares de couve. Anais da Sociedade Entomológica do Brasil, Londrina, v. 22, n. 2, p. 232-237, 1993.

FILGUEIRA, F. A. R. Manual de olericultura. 2. ed. São Paulo: Agronômica Ceres, 1982. v. 2, p. 50-53.

GALLO, D.; NAKANO, O.; SILVEIRA NETO, S.; CARVALHO, R. P. L.; BATISTA, G. C. de; BERTI FILHO, E.; PARRA, J. R. P.; ZUCCHI, R. A.; ALVES, S. B.; VENDRAMIM, J. D.; MARCHINI, L. C.; LOPES, J. R. S.; OMOTO, C. Entomologia agrícola. Piracicaba: FEALQ, 2002. 920 p.

MEDEIROS, C. A. M. Efeito inseticida de extratos vegetais aquosos sobre Ascis monuste orseis (Latreille) em couve (Brassica oleracea L. var. acephala DC.). 83p. 2004. Dissertação (Mestrado em Entomologia Agrícola), Faculdade de Ciências Agrárias e Veterinárias, UNESP, Jaboticabal, SP.

MEDEIROS, C. A. M.; BOIÇA JUNIOR, A. L.; TORRES, A. L. Efeito de extratos aquosos de plantas na oviposição da traçadas-crucíferas, em couve. Bragantia, Campinas, v.64, n.2, p.227232, 2005.

NOMURA, H.; YAMASHITA, I. Desenvolvimento do curuquerê-da-couve, Ascia monuste orseis (Linnaeus, 1764) (Lepidoptera, Pieridae), em laboratório. Revista Brasileira de Biologia, Rio de Janeiro, v. 35, n. 4, p. 799-803, 1975.

OSMAN, M.Z. Effects of neem seed extract on growth and development of larvae of Pieris brassicae L. (Lep., Pieridae). Journal of Applied Entomology, v.115, p.254-258, 1993.

OSMAN, M.Z.; PORT, G.R. Systemic action of neem seed substances against Pieris brassicae. Entomology Experimentallis et Applicata, v.54, p.297-300, 1990.

ROEL, A. R.; VENDRAMIM, J. D.; FRIGHETTO, R. T. S.; FRIGHETTO, N. Atividade tóxica de extratos orgânicos de Trichilia pallida Swartz (Meliaceae) sobre Spodoptera frugiperda (J. E. Smith). Anais da Sociedade Entomológica do Brasil, Londrina, v. 29, n. 4, p. 799-808, 2000a.

ROEL, A. R.; VENDRAMIM, J. D.; FRIGHETTO, R. T. S.; FRIGHETTO, N. Efeito do extrato acetato de etila de Trichilia pallida Swartz (Meliaceae) no desenvolvimento e sobrevivência da lagartado-cartucho. Bragantia, Campinas, v. 59, n. 4, p. 53-58, 2000b.

SALGADO, L. O. Pragas das brássicas, características e métodos de controle. Informe Agropecuário, Belo Horizonte, v. 9, n.98, p. $43-47,1983$.

SHIN-FOON, C.; YU-TONG, Q. Experiments on the application of botanical insecticides for the control of diamondback moth in South China. Journal Applied Entomology, Hamburg, v. 116, p. 479-486, 1993. 
TORRECILAS, S. M.; VENDRAMIM, J. D. Extrato aquoso de ramos de Trichilia pallida e o desenvolvimento de Spodoptera frugiperda em genótipos de milho. Scientia Agricola, Piracicaba, v. 58, n. 1, p. 27-31, 2001.

TORRES, A. L.; BARROS, R.; OLIVEIRA, J. V. de. Efeito de extratos aquosos de plantas no desenvolvimento de Plutella xylostella L. (Lepidoptera). Neotropical Entomology, Londrina, v. 30, n. 1, p. 151-156, 2001.
VENDRAMIM, J. D.; MARTINS, J. C. Aspectos biológicos de Ascia monuste orseis (Latreille, 1819) (Lepidoptera: Pieridae) em couve (Brassica oleracea L. var. acephala). Poliagro, Bandeirantes, v. 4, n.1-2, p. 57-65, 1982.

VENDRAMIM, J. D.; SCAMPINI, P. J. Efeito do extrato aquoso de Melia azedarach sobre o desenvolvimento de Spodoptera frugiperda (J. E. Smith) em dois genótipos de milho. Revista de Agricultura, Piracicaba, v. 72, n. 2, p. 159-170, 1997. 